\title{
LA ÉTICA PROFESIONAL DOCENTE PARA UN MEJOR DESEMPEÑO LABORAL
}

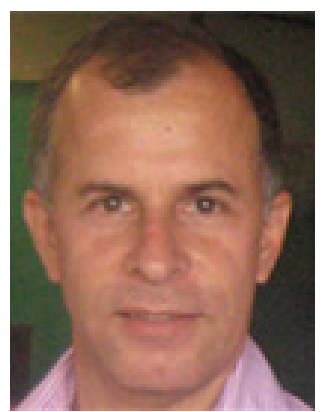

Fecha de recepción: 21/09/2017
Fecha de revisión: 17/10/2017

Fecha de aceptación: 02/11/2017

\section{RESUMEN}

Esta investigación determina mediante un estudio descriptivo y comparativo la disposición y expectativa del docente de Instituciones Educativas de Ibagué al incorporar la dimensión ética en su ejercicio profesional para ver si considera entre sus objetivos el crecimiento en las dimensiones humanas, la formación integral de estudiantes y de sí mismos con la autoreflexión como componente metodológico en su proceso de mejoramiento continuo. Posteriormente, elabora y valida una metodología destinada a promover e incorporar las competencias éticas en su ejercicio profesional que facilite el trabajo y análisis de resultados obtenidos y clasificados por categorías, para ajustar en su desempeño hacia el cambio positivo, la auto crítica, la vivencia y transmisión de valores específicos en el aula desde las áreas obligatorias contempladas en la Ley115. Finalmente aporta a los programas de formación continua de docentes de la Secretaría de Educación Municipal en las Semanas Institucionales o como propuesta metodológica de autoevaluación.

Palabras clave: Ética profesional, práctica reflexiva, desarrollo profesional integral.

\section{TEACHING PROFESSIONAL ETHICS FOR BETTER WORK PERFORMANCE}

\begin{abstract}
This research determines through a descriptive and comparative study the disposition and expectation of the teacher of Educational Institutions of Ibague to incorporate the ethical dimension in their professional practice to see if it considers among its objectives the growth in the human dimensions, the integral formation of students and themselves with self-reflection as amethodological component in their process of continuous improvement. Subsequently, develops and validates a methodology to promote and incorporate ethical competencies in their professional
\end{abstract}


practice to facilitate the work and analysis of results obtained and classified by categories, to adjust their performance towards positive change, self-criticism, experience and transmission of specific values in the classroom from the compulsory areas contemplated in the Law115. Finally, it contributes to the teacher training programs of the Municipal Education Secretariat in the Institutional Weeks or as a methodological self-evaluation proposal.

Keywords: Professional ethics, reflexive practice, comprehensive professional development.

\section{INTRODUCCIÓN}

Es imperativo asumir la formación ética y moral del docente, conforme a las exigencias que la sociedad espera de la academia, por la construcción integral de ambientes humanos, al tiempo que la direcciona. Al docente comprometido le exige formación humanística y pedagógica planeada y reflexionada en la lectura de la realidad circundante, evalúa críticamente las dimensiones que conforma su ser en el ejercicio de una demandante labor; conoce y aplica para sí mismo las inteligencias múltiples, para potenciar su mundo interno y luego a sus alumnos, dando mayor sentido a su labor docente. Con su sentir humano va más allá de la transmisión de saberes y con apertura y diálogo valora el esfuerzo de sus pares, quienes aportan al mismo objetivo educacional. Se pretende estar por encima del promedio; que quieran formar seres humanos más felices e inteligentes en medio de un mundo cada vez más estresante. Aplicamos para el docente el refrán que exige implícitamente, vivir y actuar mejor, "Ninguno da lo que no tiene" (Centurio, en La Celestina - Acto XVIII)

La propuesta es de reflexión, intervención y ajuste en la vida y obra personal y profesional de cada docente de área (Ley 115 de 1994) propendiendo un equilibrio entre estos ideales o planos a integrar; una utopía, no tanto desde lo irrealizable, cuanto que al aproximarse le catapulta a continuar en una búsqueda constante de perfección. Prestar más atención a su formación integral y evaluar el grado de compromiso práctico, que posee con estos principios éticos que cualifican su labor profesional. En la región, la formación de formadores será un factor de mayor impacto social, toda vez que la forma en que ese grupo se desarrolla y crece, genera un mayor bienestar social. Merece fortalecer procesos en su desempeño ético profesional con encuentros y ambientes más dispuestos, comprometidos y organizados por las (I.E) Instituciones Educativas en respuesta a su mejoramiento desde la dimensión ética.

\footnotetext{
${ }^{1}$ Armstrong, Thomas (2013). Inteligencias Múltiples en el Aula: Guía práctica para educadores. 5a . Edición. Ed/ Paidós. Barcelona. Pág. 37
} 
La oportuna intervención que evalúe el resultado práctico vivido por cada I.E permite ver mejoras cuantitativas y cualitativas. Exige reconocer la práctica docente como un proceso que se da en medio de intereses para alcanzar resultados cuantitativos; por tanto, el docente sabe que la formación moral y su actuar ético desempeñan un papel dinamizador cualitativo en su buen vivir y mejor desempeño, quien con su ejemplo es capaz de construir y ejercer su condición humana más íntegra y de mayor cultura. Cualificar la formación integral del docente en cada I.E del Municipio de Ibagué, facilitará su trabajo, ánimo y logros. "He aspirado siempre a un pensamiento multidimensional... Sólo el pensamiento complejo nos permitirá civilizar nuestro conocimiento". (E. Morin 1998: 23/35)

\section{Fundamentación y consulta de fuentes}

La revisión bibliográfica relacionada al tema de investigación permite ver el aporte de otros procesos que describen y perfeccionan la evaluación del desempeño docente señalando diferencias significativas en cuanto a la apreciación evaluativa realizada a su labor. Confirma que los estudiantes consideran de enorme y positiva influencia para su trayectoria profesional, la visión previa a partir de su profesorado como modelo de formación científica y profesional a seguir (Marchesi, 2008; Martínez, 2010 y Álvarez, 2015). Busca la mejor formación ética en el docente, que favorezca condiciones especiales en la promoción y construcción de valores mínimos para alcanzar mayor nivel en la dignidad humana desde las I.E para la sociedad. Exige incluir en el currículo universitario el componente de formación ética y la revisión honesta de quienes ya ejercen la profesión.

En efecto, la profundización del estudio en la ética profesional con la autorreflexión, enriquece la práctica docente, pero requiere estimular la crítica, personal y compartida, sobre la propia actitud vital y las actitudes morales del profesional en el contexto que rodea a la enseñanza y con la posibilidad de cambiar en positivo lo que es mejorable. Una aproximación la encontramos en Carlos E. Rojas Artavia (2011), con la "Ética Profesional Docente: Un compromiso pedagógico humanístico" allí reafirma que la ética profesional es un compromiso vivencial que va más allá de la norma escrita y que debe armonizar lo teórico y práctico. El docente será consciente de sus tenencias prácticas, intelectivas y morales, y del deber de desarrollo constante para bien de sus estudiantes en procura de crecer cognitiva, afectiva y moral e integralmente. Frente a la conducta del docente, su Código de Ética indica la pertinencia en la observación de buenas conductas dentro y fuera de su lugar de trabajo, esto fortalece el prestigio profesional y el mal ejemplo la menoscaba.

Guadalupe Chávez y Benigno B. (2011) investigaron la "Docencia universitaria frente al cambio: Exigencia profesional y Compromiso Ético" Su resultado hace parte del programa del Cuerpo Académico de Educación 'Cambio Educativo' de la Facultad de Filosofía de la Universidad Autónoma de Nuevo León, México expuesto en el XI Congreso Nacional de Investigación educativa, luego de entrevistas entre 2009 y 2010, vinculadas al proyecto interinstitucional de Ética Profesional en Posgrado, coordinado por Hirsch Adler. 
El docente ve primero el compromiso institucional y luego pasa a los estudiantes y colegas. También Vázquez Verdera, Escámez Sánchez y García López (2012) analizan el hecho educativo: "Educación para el cuidado. Hacia una nueva pedagogía." Intervienen con preguntas: ¿Cómo mi asignatura puede servir a las necesidades de cada uno de mis estudiantes? ¿Cómo puedo ayudarles en la promoción de su inteligencia? ¿Cómo lograr contacto con la mayor parte del alumnado? ¿Cómo ayudar a que cuiden de sí mismos, de otras personas, de los animales, del entorno natural, del recreado por el ser humano y del maravilloso mundo de las ideas? El cuidado es clave en la ética y una exigencia insatisfecha en la sociedad actual. El procedimiento metodológico es la hermenéutica crítica para detectar principios éticos y valores cívicos compartidos sobre el cuidado.

Finalmente, Arelmí Beltramé (2017) con la “Ética profesional y su relación con el desempeño docente en las instituciones públicas de Juliaca - Perú" presenta la problemática y exigencia actual educativa e invita a reflexionar sobre la ética y la praxis docente de forma cualitativa y consciente como determinante para su mejoramiento. Es tanto de responsabilidad como de obligatoriedad. El estudio valida análisis previos y teóricos de investigaciones sobre lo ético como un camino eficaz y pertinente en el quehacer docente con valores que debe encarnar dentro y fuera del aula como riqueza y mayor aporte para sí, sus estudiantes, la Institución, la comunidad y sociedad en general.

\section{El Contexto de la situación Problemática}

La ética profesional docente, es un compromiso vivencial que trasciende las reglas escritas acerca del ejercicio de su profesión y espera que la puesta en práctica durante el desempeño, arroje evidencias acerca de su excelencia e integralidad. El maestro consciente de sus capacidades prácticas, intelectivas y morales, las desarrolla en su propia vida, por tanto, sólo con el ejemplo puede llegar a convertirlas en el fundamento del ejercicio profesional irradiando al estudiante para crecer de manera integral.

La percepción en los docentes consultados informalmente en Ibagué, indica que los principios éticos no se aprenden tanto a través de procesos formativos sistematizados cuanto por la propia experiencia. En la primera aproximación indicaba que poseían un aceptable dominio del tema de los valores y sin la necesidad de más procesos formativos. Sin embargo, luego de encuentros con trabajo individual y colectivo de reflexión, ven un panorama más amplio y de impacto significativo para su ejercicio profesional. Esto nos lleva a interrogarnos ¿Hasta qué punto los docentes del Municipio de Ibagué poseen la preparación que permita asumir de manera eficiente la responsabilidad de administrar recursos éticos y morales con la misma destreza con que administran los recursos cognitivos, técnicos y metodológicos propios de la profesión? Para el diagnóstico de éste interrogante, se invita al grupo a realizar una jornada experimental de reflexión para examinar y compartir experiencias de aprendizajes sobre formación ética profesional por y para docentes y desarrollar un mecanismo que permita hacer aflorar la toma de conciencia sobre la problemática y fortaleza en el proceso de desempeño ético profesional 
de conciencia sobre la problemática y fortaleza en el proceso de desempeño ético profesional con encuentros en las mismas I.E desde algunos interrogantes fundamentales:

- ¿Qué nivel e importancia le otorga el profesorado de las I.E del Municipio de Ibagué a la Ética Profesional Docente y cómo la incorpora en su formación integral tanto personal como profesional?,

- ¿Hasta qué punto el profesorado aborda, desde la perspectiva de la Ética Profesional, el tratamiento de las inteligencias múltiples como cualidad notoria y la diversidad de las dimensiones humanas en su desempeño docente?

- ¿Desde la reflexión acerca de la experiencia y el contexto del ejercicio docente, se pueden validar o generar pautas y metodologías que faciliten la formación integral de los docentes y refuercen su compromiso ético laboral?

De esta manera surge la pregunta fundamental de nuestra investigación:

¿Es posible que mediante procedimientos de reflexión acerca de la incorporación de la ética profesional docente como un componente fundamental de su ejercicio docente y del diálogo sobre las experiencias significativas educativas, se pueda generar y validar algunas directrices y metodologías que enriquezca el proceso de cualificación de la formación integral del maestro de las I.E de la Ciudad de Ibagué?

\section{Objetivos y Síntesis del proceso metodológico en la investigación}

El carácter descriptivo y cualitativo de la investigación, tiene en cuenta la unidad de análisis centrado en la socialización de experiencias, las actuaciones del docente o roles que desempeña, los sentimientos y valores que evidencia e inciden en su vida personal y en su ejercicio profesional. Abarca el análisis con encuesta, estudio de casos conforme a sus experiencias, estudios comparativos y de desarrollo.

\begin{tabular}{|c|c|c|c|}
\hline Objetivos específicos de la investigación & $\begin{array}{l}\text { Etapas de } \\
\text { recolección }\end{array}$ & $\begin{array}{l}\text { Fase del } \\
\text { proceso }\end{array}$ & $\begin{array}{l}\text { Instrumento } \\
\text { recolección }\end{array}$ \\
\hline $\begin{array}{l}\text { Hacer un estudio descriptivo y comparativo } \\
\text { acerca de la conciencia en docentes de las I.E de } \\
\text { lbagué sobre la importancia de involucrar la } \\
\text { dimensión ética en el modo de concebir y realizar } \\
\text { su labor docente de aula y en el contacto con la } \\
\text { comunidad educativa. }\end{array}$ & $\begin{array}{l}\text { Abordaje a la } \\
\text { identidad ética } \\
\text { profesional de } \\
\text { docente }\end{array}$ & $\begin{array}{l}\text { La identidad } \\
\text { ética } \\
\text { profesional }\end{array}$ & $\begin{array}{l}\text { Entrevista } \\
\text { individual y } \\
\text { encuentros } \\
\text { grupales. }\end{array}$ \\
\hline $\begin{array}{l}\text { Inducir a reflexionar en aportes, para su } \\
\text { desarrollo profesional y su proyección formativa, } \\
\text { al involucrar la dimensión ética en su desempeño } \\
\text { y del conocimiento acerca de las múltiples } \\
\text { facetas y complejidades de la dimensión } \\
\text { humana, sobre las inteligencias múltiples como } \\
\text { cualidad sobresaliente y sobre las prácticas } \\
\text { reflexivas a desarrollar para ampliar su propio } \\
\text { crecimiento personal y a su desempeño docente }\end{array}$ & $\begin{array}{l}\text { Abordaje a las } \\
\text { prácticas } \\
\text { reflexivas } \\
\text { docentes e } \\
\text { inteligencias } \\
\text { múltiples }\end{array}$ & $\begin{array}{l}\text { Planeación y } \\
\text { elaboración } \\
\text { herramienta }\end{array}$ & $\begin{array}{l}\text { Entrevista } \\
\text { semiestructur } \\
\text { ada }\end{array}$ \\
\hline $\begin{array}{l}\text { Resaltar y socializar las experiencias } \\
\text { significativas y logros relacionados a las prácticas } \\
\text { y a la vivencia de la ética en el ejercicio } \\
\text { profesional en las I.E. }\end{array}$ & $\begin{array}{l}\text { Análisis en } \\
\text { prácticas y } \\
\text { experiencias } \\
\text { laborales }\end{array}$ & Categorías & $\begin{array}{l}\text { Observación } \\
\text { y Entrevista } \\
\text { semiestructur } \\
\text { ada }\end{array}$ \\
\hline $\begin{array}{l}\text { Proponer la inclusión de procedimientos de } \\
\text { concientización y desarrollo ético profesional } \\
\text { docente puestos en prácticas en esta } \\
\text { investigación a la Secretaría de Educación a fin } \\
\text { de enriquecer sus programas de evaluación y } \\
\text { desarrollo de la Calidad Educativa }\end{array}$ & $\begin{array}{l}\text { Análisis y } \\
\text { propuesta de } \\
\text { herramientas } \\
\text { de trabajo en } \\
\text { evaluación } \\
\text { docente. }\end{array}$ & $\begin{array}{l}\text { Categorías y } \\
\text { frecuencias }\end{array}$ & $\begin{array}{l}\text { Matrices de } \\
\text { análisis. }\end{array}$ \\
\hline
\end{tabular}


La forma de ver la misión y labor docente demanda innovaciones organizacionales y una conciencia colectiva que trasciende a la praxis educativa. El objetivo es la cualificación en la formación integral en coherencia con su vida ejemplar y toma de conciencia de su práctica reflexiva en una constante autocrítica que pretenda resolver: ¿Enseñar valores vivencialmente desde su área específica de conocimiento, es su competencia? ¿Se trabaja la competencia ética en el proceso formativo docente en sus I.E y en relaciones humanas, laborales y profesionales? Luego es referente el maestro como modelo ético. "La meta social de la docencia consiste en la transmisión de la cultura y la formación de personas críticas" . Este bien legitima la docencia si se pretende ser profesional competente y ético en direccionar la promoción del pensamiento crítico del alumno, con un razonamiento bueno, con habilidades para observar e inferir, generalizar, expresar hipótesis, concebir alternativas, evaluar afirmaciones, detectar problemas y percibir la acción apropiada. Supone curiosidad intelectual, objetividad, flexibilidad, honestidad, respeto del punto de vista de otros.

El MEN (Ministerio Educación Nacional), procura que los nuevos docentes y directivos sean más conscientes del valor del mejoramiento continuo y busca con las Evaluaciones anuales de desempeño confrontar su realidad personal y laboral para hacer ajustes posibles, esto puede también ser parte de una metaevaluación por temas como el aprendizaje, mejora de procesos, rigor en técnicas e instrumentos usados, la valoración y, por supuesto, la ética como propuesta asumida por el propio docente, gestor de cambio. La claridad sobre los fines o la dimensión teleológica docente: ¿Qué pretende lograr como objetivo último de sus prácticas? ¿Qué bienes intenta realizar? ¿Para quién trabaja y desde dónde lo hace? Fines que difieren según sea el nivel, primaria, secundaria o superior. Lo que formula la propuesta del MEN de la formación a través del sistema de formación:

Cuadro 1: Sistema de Formación de Educadores
\begin{tabular}{|c|l|l|}
\hline Subsistema & \multicolumn{1}{|c|}{ Objetivos } & Programas/Preparación \\
\hline $\begin{array}{c}\text { Formación } \\
\text { inicial }\end{array}$ & $\begin{array}{l}\text { Adquirir fundamentos y saberes básicos para } \\
\text { el desarrollo de la competencia profesional } \\
\text { docente básica para el desempeño } \\
\text { profesional en un saber específico. }\end{array}$ & $\begin{array}{l}\text { Normal Superior y } \\
\text { Universidades con } \\
\text { licenciatura y pedagogía } \\
\text { para no licenciados. }\end{array}$ \\
\hline $\begin{array}{c}\text { Formación } \\
\text { continua }\end{array}$ & $\begin{array}{l}\text { Actualiza y perfecciona en la disciplina y en } \\
\text { pedagogía sus competencias y lo cualifica } \\
\text { como profesional, al tiempo beneficia a la } \\
\text { I.E., donde labora }\end{array}$ & $\begin{array}{l}\text { Práctica reflexiva sobre su } \\
\text { ejercicio profesional } \\
\text { docente. }\end{array}$ \\
\hline $\begin{array}{c}\text { Formación } \\
\text { avanzada }\end{array}$ & $\begin{array}{l}\text { Implementar procesos de investigación, } \\
\text { innovación y gestión educativa. }\end{array}$ & $\begin{array}{l}\text { Posgrado: Especialización } \\
\text { maestría, doctorado }\end{array}$ \\
\hline
\end{tabular}

Es justo revisar con prontitud y honestidad el compromiso relacionado con las competencias éticas en el ejercicio profesional. Se enfrenta a un desequilibrio que no puede desalentar la labor docente y que al contrario lo reta y le hace más necesario e idóneo en su ser y quehacer. Reconocer la práctica docente como un proceso que se da en medio de la dificultad, donde convergen varias posiciones encontradas que ponen en evidencia la necesidad de aproximarse al maestro a la luz del contexto y del marco institucional en los que

\footnotetext{
${ }^{2}$ García López, R. Jóver, G. y Escámez; J. (2010): Etica profesional docente. Síntesis. Madrid.

${ }^{3}$ Concepto introducido por Scriven (1968) al afirmar que "los evaluadores tienen la obligación profesional de que las evaluaciones propuestas o finalizadas estén sujetas a una evaluación competente, la metaevaluación"... la evaluación es un tema particularmente auto-referente, puesto que se aplica a todos los esfuerzos humanos serios y, en consecuencia, a la propia evaluación

${ }^{4}$ Nussbaum Martha C. (2011) "Sin fines de lucro. Por qué la democracia necesita de las humanidades". Rev. Signo y Pensamiento, vol. XXX, núm. 58, enero-junio, 2011, pp. 328-331
} 
desarrolla su quehacer de forma reflexiva y de intervención. Enseñamos lo que somos, en los distintos niveles de enseñanza, con una alta y creciente responsabilidad social y ética al formar alumnos que toman parte en la construcción de un mundo mejor.

La educación integral contempla fines y propósitos educativos para perfeccionar al hombre. Según Freire (1921-1997), "La educación es lograr que las personas sean felices. Su único propósito debe siempre ser el de alcanzar la igualdad, la transformación y la inclusión de los individuos en la sociedad". Actuando conforme y en favor de nuestra sociedad y cultura humana, alcanzaría en todos mejores niveles de competencias saludables, porque cada quien buscaría su formación profesional pensando más en el bien común. Así, al maestro, formador y facilitador con una profesión de gran valor y dignidad, le es esencial tener una vida ejemplar fundamentada en razones de carácter ético.

La demanda social por una adecuada formación ética del educador, implica también al sistema educativo que ofrece el servicio. Componentes sistemáticos para la formación pedagógica, lo cognoscitivo, moral, ético y habilidades técnicas integradas para ofrecer un mejor servicio educativo, que tiene en cuenta la investigación, priorizando la dimensión ética para el profesional, pese a ser la gran olvidada en todas las reformas; que como diría Hortal (2015) no sólo queremos buenos profesionales, también profesionales buenos, que se comprometan por el mundo, poniendo su formación y conocimientos a su servicio y a mejorar la sociedad en equidad. Así, la ética del profesional docente se construye entre todos los ciudadanos a quienes afectan las decisiones sobre enseñanza y aprendizaje; como una reflexión en torno a las buenas prácticas para que el proceso de enseñanza-aprendizaje llegue al mejor objetivo (García, Olmeda, y Escámez) .

Philippe Perrenoud define la competencia, como la capacidad para movilizar varios recursos cognitivos (conocimientos, técnicas, habilidades, aptitudes) para hacer enfrentar tipos de situaciones. Las agrupa en diez familias que perfeccionan sus procesos:

1) Organizar y animar situaciones de aprendizaje.

2) Gestionar la progresión de los aprendizajes.

3) Elaborar y hacer evolucionar dispositivos de diferenciación.

4) Implicar a los alumnos en sus propios aprendizajes.

5) Trabajar en equipo.

6) Participar en la gestión de la escuela.

7) Informar e implicar a los padres.

8) Utilizar los avances tecnológicos.

\footnotetext{
${ }^{5}$ Vitoria-Gasteiz, (2013). Mejora de la práctica docente Una experiencia de autoevaluación. Gobierno Vasco.

${ }^{6}$ El concepto de "profesión" proviene según Weber, de la tradición luterana, entendida como trabajo cotidiano en el mundo. El más noble contenido de la propia conducta moral consiste en sentir como un deber el cumplimiento de la tarea profesional en el mundo, otorgando un carácter sagrado al trabajo y un sustrato ético-religioso a la profesión. ${ }^{7}$ Hortal, A (2015) Ética general de las profesiones., Bilbao; Desclée De Brouwer. P. 62

8 García L, R., Olmeda, G. y Escámez, J. (2010). Ética profesional docente. Madrid. Editorial Síntesis

9 Perrenoud, Philippe (2011). Desarrollar la práctica reflexiva en el Oficio de Enseñar. Crítica y Fundamentos 1. $4^{\mathrm{a}}$. Reimpresión. Editorial Graó. Barcelona. 224 p
} 
9) Afrontar los deberes y los dilemas éticos de la profesión.

10) Organizar la propia formación continua.

El objetivo es, coparticipar y hacer dialogar entre sí estos saberes para conciliar con la práctica reflexiva, la razón científica con la razón práctica; el conocimiento de procesos universales con los saberes de la experiencia y la ética hacia mejores prácticas educativas como asesor, formador o responsable de proyectos innovadores y directivos. El primer profesional, llamado a estar formado en principios y valores humanos es el maestro, quien jalona el sentido humano de la institución. La investigación busca cómo empoderar a las áreas obligatorias (Ley 115 Art. 23) e integrarlas con lo ético, con docentes ejemplo digno de admirar y seguir por su entrega o vocación. El MEN, busca crear las condiciones necesarias para facilitar al educador su vida de persona de reconocida idoneidad moral, ética, pedagógica y profesional hacia un servicio educativo de calidad. Responsabilidad del educador, de la Nación, de las entidades territoriales y de las instituciones educativas (Art. 110 Ley 115 de 1994). Así, los desafíos y demandas sobre la enseñanza y el aprendizaje que exigen nuevas capacidades y competencias. Marchesi, las relaciona en lo siguiente :

a) Mediar y colaborar,

b) Diseñar y gestionar sus propios recursos,

c) Con una didáctica basada en la investigación,

d) Utilizar el error como fuente de aprendizaje,

e) Fomentar la autonomía del alumno y su actitud crítica,

f) Tener competencias básicas en las TIC y

g) Ser creadores de actividades motivadoras.

Enseñamos lo que somos. Si al docente no le gusta trabajar en equipo, le será difícil enseñar cómo se constituye un grupo, planificar un proceso, asignar responsabilidades, hacer reuniones de trabajo, desarrollar y evaluar productos. Exige interés sobre temas como lo ético, estético y político en el campo humano; competencias que constituyen configuraciones de la personalidad profesional que lo hacen idóneo para el desarrollo de la actividad pedagógica que se manifiestan en su desempeño y se evidencia en la actividad exitosa en procesos de la integración cognitivo, creativo, afectivo, operativo, en la solución de problemas. Armstrong (2013) dice: "Antes de aplicar un modelo de aprendizaje en el aula, debemos empezar por probarlo en nosotros mismos como educadores y estudiantes adultos". Se podría diferenciar entre:

-Competencia académica: Domina contenidos propios de su asignatura y es motivante. Lee y ofrece elementos del área con relación a las realidades y el entorno en general.

-Competencia didáctica: Manejo de los componentes personales y no personales del proceso de enseñanza-aprendizaje, lo que facilita la enseñanza.

-Competencia organizativa: Dominio en la planificación, organización, ejecución y control de las acciones pedagógicas y didácticas involucradas en la formación del que aprende.

-Competencia práctica: Capacidad de aplicar conocimientos, destrezas y actitudes al desempeño de la ocupación que se trate.

\footnotetext{
${ }^{10}$ OEI. (2010). Educación, valores y ciudadanía. Madrid: Fundación SM.

11 Marchesi, A. (2007). Sobre el bienestar de los docentes. Competencias, emociones y valores. Madrid: Alianza Editorial. Págs. 192.

${ }^{12}$ Armstrong (2013) Pág. 34.
} 


\section{MÉTODO Y SISTEMA DE VARIABLES.}

Desde las encuestas y entrevistas se extraen datos fundamentales para estudiary operacionalizar esos mismos conceptos a variables que se puedan descomponer en indicadores a través de un proceso de deducción lógica para llegar a los indicadores. Variables como niveles de satisfacción, expectativas cumplidas dentro y fuera de las aulas, el desempeño docente de calidad en los programas, su tiempo de la formación y el trabajo de mejoramiento. El carácter fundamentalmente descriptivo y cualitativo, busca identificar y analizar los modelos y necesidad formativas que implementan y desarrollan profesores de diversos programas académicos que asumen con mayor o menor rigor en sus Instituciones. El trabajo de carácter mixto en la etapa inicial presenta cuestionarios para los docentes. Cualitativo en la metodología al obtener aportes de mejora de los procesos de formación continua.

El proceso del estudio se ha desarrollado en varias fases:

- De revisión de la literatura: se analizaron diferentes documentos y bibliografía relacionada con el tema de investigación.

- De exploración inicial: Se realizaron 25 entrevistas a docentes y a 6 directivos docentes para adaptar los planteamientos teóricos a la realidad y vida de los centros.

- Extensiva: Recoge información mediante 3 cuestionarios administrados a la población descrita. El estudio de tipo cuantitativo tiene por objeto describir las características de la formación del docente del área y su mejor impacto.

- Integradora y propositiva: Integra informaciones de fases anteriores con propuestas de mejora para el abordaje de la formación docente continua en sus instituciones.

En la etapa inicial se realizan visitas a las I.E, encuentros con docentes y directivos para una presentación general e intencionalidad del trabajo investigativo; diseña encuestas y socializa cuestionarios, que se aplican a docentes. Una confrontación en lo documental que se realiza en un periodo de 3 años (2015-2018). Se genera una herramienta que facilita la revisión y análisis de mayor profundidad de las ciencias y aportes que dan en el tema de la cualificación o mejoramiento de la educación, desde el compromiso personal. El proceso del estudio se ha desarrollado en varias fases que se dan conforme a criterios, así:

- Fase 1: Diagnóstico sobre el tema o problemática encontrada y su estado del arte. Lo que permite describir, analizar y delimitar la problemática y alcances de la investigación.

- Fase 2: Diseño. Con la recolección de información, se prepara el material. Se organiza y sistematiza la información guiados por las variables encontradas. Crítica y discusión.

- Fase 3: Gestión e implementación, organizada la información categorial continúa con análisis más consistente y profundo para establecer relaciones y frecuencias.

- Fase 4: Entrega de informes parciales o total del trabajo investigativo para revisión, ajustes o aprobación de la propuesta, su validación y finalización.

- Fase5:Seguimientoomonitoreodelapropuesta,delaaplicacióndeinstrumentos,herramientas oprocesosqueintervienenenelcambioymejoradeunarealidadproblémicaencontradaenlafase 1. 
Cuadro 2: Proceso y Análisis de momentos en la metodología

\begin{tabular}{|c|c|}
\hline Etapa & Momentos de desarrollo (descripción) \\
\hline Análisis preliminar & - Transcripción \\
\hline $\begin{array}{l}\text { Microanálisis } \\
\begin{array}{l}\text { Análisis en } \\
\text { profundidad }\end{array}\end{array}$ & $\begin{array}{l}\text { - Exploración, revisión de lecturas y otros, análisis guía. } \\
\text { - Obtención de categorias iniciales conforme a objetivos propuestos } \\
\text { - Relectura de material e información conforme a ajustes con asesores } \\
\text { - Diseño de matrices para análisis y agrupación. } \\
\text { - Definición previa de categorías } \\
\text { - Estudio de concordancia y definición porcentual } \\
\text { - Ajuste a las categorías con participación de docentes interesados } \\
\text { - Definición de categorias y ajustes a entrevista e instrumentos }\end{array}$ \\
\hline
\end{tabular}

La estrategia que favorece la recolección de información, es la observación que toma elementos de los encuentros individuales y grupales en las entrevistas (grabación de audio, audio video y de registro de notas) vinculadas al tema central sobre ética profesional.

\section{Cuadro 3: Síntesis. Análisis y uso de información según la Observación.}

\section{Etapa de análisis de información según la Observación}

- Transcripción del material obtenido y organización del mismo

- Distribución de la información conforme a grandes aspectos instruccionales

- Asignación de frecuencias para determinar orden de importancia y validación

- Validación de aspectos con aporte y juicio de algunos docentes

- Ajuste y validación para el registro conforme al aspecto del campo disciplinar

- Ubicación de aspectos en las categorías obtenidas para el instrumento propuesto

La selección del diseño de la Investigación refiere a la Metodología de Investigación de Hernández, Fernández y Baptista ${ }^{13}$ según los autores el diseño adecuado para esta investigación es de tipo Teoría Fundamentada, el rasgo principal es que los datos se categorizan con codificación abierta. El investigador organiza las categorías en un modelo de interrelación (codificación axial), que representa a la teoría emergente y explica el proceso o fenómeno de estudio (codificación selectiva). Un punto de partida que encuentra reacciones: ¿Qué herramienta? ¿De qué tipo estamos hablando? ¿Por qué evaluarnos a nosotros mismos? ¿Qué se puede analizar de la ética Profesional docente? ¿Qué es prioritario para cada Centro? Parte de las actividades de aula y de su ser vocacional como docente en torno al ejercicio o labor pedagógica o sus prácticas, e impulsa las etapas de reflexión y mejora a partir del mismo proceso al tiempo que se piense en el diseño o creación de las herramientas para la institución educativa (I.E).

\footnotetext{
${ }^{13}$ Hernández Sampieri R., Fernández Collado C., Baptista Lucio P. (2014) Metodología de la Investigación. 6 a Ed. Mc Graw Hill. México. pp.600.
} 


\section{RESULTADOS CONFORME A LAS UNIDADES DE ESTUDIO}

Son 31 docentes participantes (31,95\%) correspondiente a la muestra representativa de los 97 docentes que inician en el año 2015. Los aspectos relacionados, son relevantes, tiene que ver con la buena formación académica, la pertinencia en los programas que ofrece la Universidad o Normal Superior para los nuevos docentes, la vocación o perfil del maestro, fortalezas manifiestas como personas o profesionales, entre otras.

Cuadro 4: Variables encontradas en entrevista a 31 docentes

\begin{tabular}{|l|c|r|}
\hline Elementos relacionados sobre el buen Desempeño docente. & No & \multicolumn{1}{|c|}{$\%$} \\
\hline Programas pertinentes que ofrece la Universidad o Normal Superior & 26 & 83,88 \\
\hline Formación Universitaria es deficiente y depende del esfuerzo y perfil. & 02 & 6,45 \\
\hline Resultan útiles otros programas académicos y gusto por enseñar & 03 & 9,67 \\
\hline Es útil contar con disposición, destrezas y habilidades personales & 20 & 64,50 \\
\hline El mayor logro lo alcanza el maestro como actor - dinamizador ético & 08 & 25,80 \\
\hline No sabe o no responde & 03 & 9,67 \\
\hline
\end{tabular}

Los profesionales docentes pertenecientes a 3 de 56 I.E del Municipio de Ibagué, presentan características similares por ubicación, nivel socio económico, se direccionan con un PEI (Proyecto Educativo Institucional) coherente conforme a las políticas estatales del MEN; están vinculados al sector oficial en el nivel de secundaria y en ellos la mayor parte con las áreas obligatorias y fundamentales (Ley 115/94, Art 23) En el año 2015, eran 429 docentes participan en charlas y encuentros generales para informar del propósito y trabajo investigativo; para 2016 y 2017 se centra para trabajar con un número de 97 (100\%) la Población con experiencias analizadas, se distribuyen, así: 16 son de Ciencias Sociales, y Filosofía, 14 de ciencias naturales, 18 de Lengua Castellana, 8 de Tecnología e Informática, 10 de religión, 10 de ética y valores, 9 de Cátedra de la paz y 12 de Matemáticas. Durante los años 2016 y 2017, se define la muestra toda vez que requiere de voluntad para su autoevaluación y aportes. La muestra o 31,95\% refieren a la buena formación académica, la pertinencia en los programas que ofrece la Universidad o Normal Superior para los nuevos docentes $(83,8 \%)$, la vocación o perfil del maestro $(2 \%)$, de sus fortalezas manifiestas como personas o profesionales $(3 \%)$, entre otras. El proceso de recolección de información se realiza en 5 momentos con etapas continuas en las que se usan estrategias como la entrevista, la encuesta y la observación.

1) La observación: Percibe las habilidades conceptuales, procedimentales y actitudinales del docente para brindar orientación y realimentación conforme a sus líneas de interés y de reflexión. Los instrumentos sobre Inteligencias Múltiples IM, prácticas reflexivas, ética profesional docente y el desempeño, permiten la autoevaluación.

3) El IALED, presenta una escala de estimación; parte I y II con las Competencias de Gestión y las Colaborativas, identifican la frecuencia y niveles de aceptación.

4) Portafolio: los Instrumentos acompañantes y el mismo IALED, es un todo integrado que ayuda a visualizar las habilidades, esfuerzos, progresos y logros del maestro y le prepara para una evaluación externa de su labor. 
5) Pruebas escritas y orales: Herramientas e instrumentos diseñados para compartir experiencias valiosas o exitosas que apuntan al mejoramiento de la calidad educativa.

Para la validez y confiabilidad la fuente documental de la investigación es lo que los docentes "dicen de lo que hacen" con un formato e intenciones particulares y resultados que presentan por considerarlos indicadores del esfuerzo, del sustento teórico dado a sus prácticas y de lo que son sus prácticas y la reflexión sobre ellas. Sobre el contexto en el que se enmarcan las propuestas, las experiencias nacen de motivaciones personales (80\%), y se justifican desde los contextos académicos $(51,4 \%)$ y socioculturales $(26 \%)$; pocas experiencias se derivan de las necesidades de exigencias institucionales (11,5\%) y mucho menos de políticas públicas (2,3\%). Los resultados advierten cierta autonomía por parte de los maestros, pero, a la vez cierta soledad en la configuración de sus propuestas. Esto tendría cierta relación con el poco diálogo interdisciplinar de las áreas (art. 23 Ley 115).

Se dan pocas relaciones entre las áreas, con un porcentaje $(43,2 \%)$ y tan solo un $18,8 \%$ enuncia una relación de esta naturaleza. El trabajo interdisciplinar es escaso con un porcentaje muy bajo de evidencia $(8,3 \%)$ y solo registran algunas iniciativas de proyectos transversales $(9,7 \%)$ que demandan el reconocimiento de otros espacios que trascienden el aula y que el maestro privilegia con el conocimiento temático y el trabajo profesional. Las experiencias restantes $(20 \%)$ involucran a otros actores como: docentes, la familia, la comunidad en general o a otro tipo de organizaciones. Los mismos docentes creen que el impacto de las experiencias es el 51\% en alumnos, para la comunidad educativa se ve impactada en un $18 \%$, y en un $31 \%$ el impacto trasciende la escuela y llega a la familia.

\section{Cuadro 5: Énfasis en Evaluación IALED según Régimen Docente}

\begin{tabular}{|c|c|c|c|}
\hline \multirow{5}{*}{ 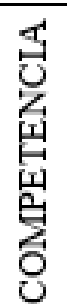 } & Régimen pensional & Decreto $2277 / 1979$ & Decreto $1278 / 2002$ \\
\hline & Docentes encuestados (31) & 14 & 17 \\
\hline & Competencia curricular & $35,7 \%(5)$ & $35,3 \%(6)$ \\
\hline & Competencia de Gestión & $35,7 \%(5)$ & $29,4 \%(5)$ \\
\hline & Competencia Colaborativa & $28,5 \%(4)$ & $35,3 \%(6)$ \\
\hline
\end{tabular}

En la entrevista de 31 docentes, con el tema relevante de lo ético como persona y profesional, arroja la siguiente información: $20(64,5 \%)$ ve fundamental lo ético, en todo cuanto se es y hace y $11(35,49 \%)$ involucran factores como capacitación, habilidades, destrezas y creciente desempeño por aprendizajes directos.

Cuadro 6: Caracterización de los docentes participantes de las áreas

\begin{tabular}{|l|l|l|l|l|l|l|l|l|l|}
\hline No. & \multicolumn{3}{|l|}{ Sexo } & \multicolumn{3}{l|}{ Edad (en Años) } & \multicolumn{4}{l|}{ Experiencia docente en años } \\
\hline \multirow{3}{*}{31} & $\mathbf{M}$ & $\mathbf{F}$ & $\mathbf{- 3 5}$ & $\mathbf{3 6} \mathbf{- 5 0}$ & $\mathbf{5 1}+$ & $\mathbf{2}$ a $\mathbf{8}$ & $\mathbf{9}$ a $\mathbf{~ 5}$ & $\mathbf{1 6}$ a 25 & + de 26 \\
\cline { 2 - 10 } & 13 & 18 & 14 & 10 & 7 & 13 & 10 & 5 & 3 \\
\hline
\end{tabular}


Frente al tema de la primacía dada a la ética docente como pilar del ser y quehacer educativo, se refiere también a las entidades estatales, los organismos no gubernamentales y las entidades privadas como actores; lo que evidencia en el docente, reconocer:

a) Un círculo ético y político en su entorno institucional que la trasciende.

b) Una educación integral desde la dimensión ética, para mejorar la convivencia.

Tabla 1: Primacía dada por áreas al tema de la ética profesional docente

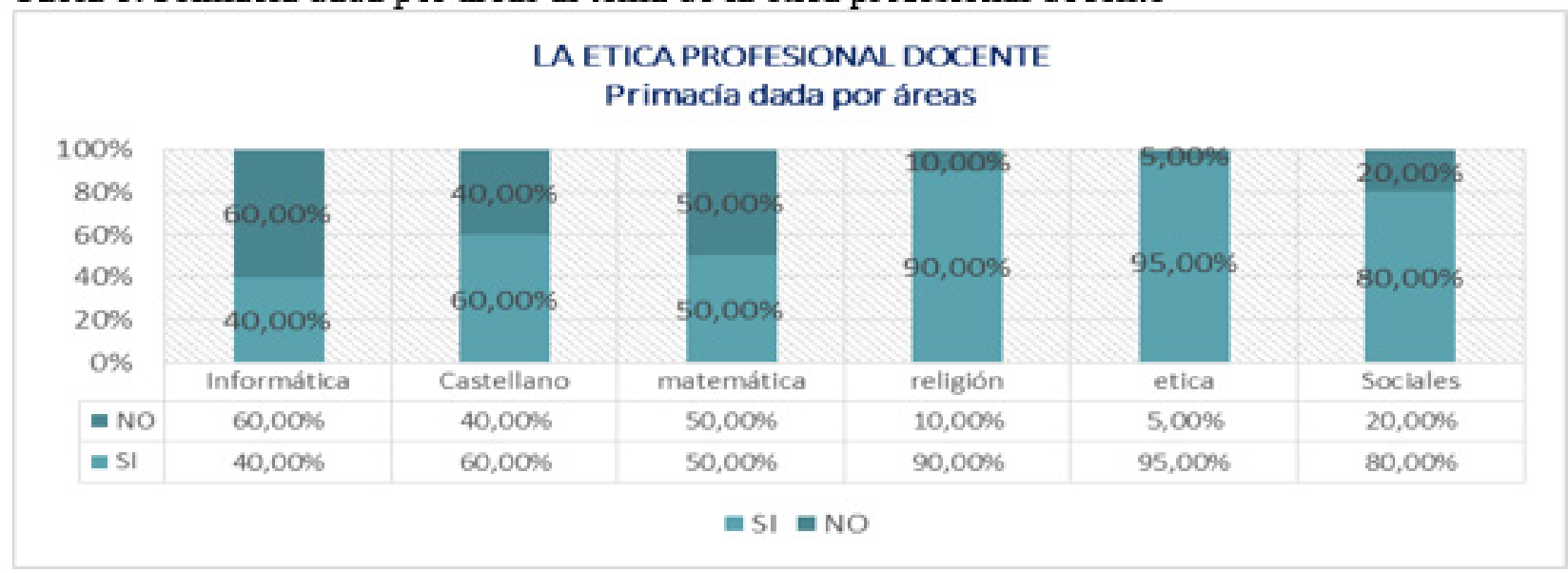

Las diferentes áreas privilegian sus experiencias y justifican sus acciones a partir de condiciones académicas y del resultado evaluativo en pruebas de estado y de aprobación o promoción escolar, el promedio no es significativamente alto con solo el 58,68\%.

Tabla 2: Reflexión sobre la práctica docente por áreas.

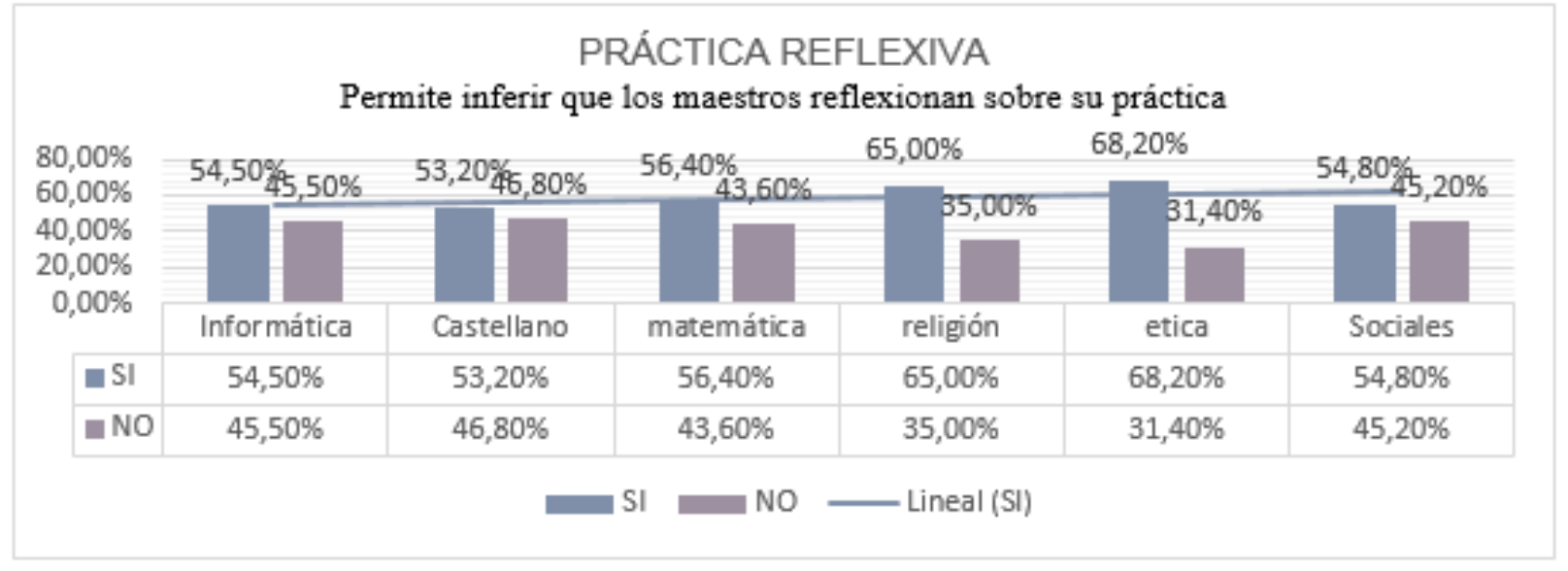

El hecho invita a retomar la propia práctica para volverla objeto de reflexión en los maestros en ejercicio para la transformación de sus prácticas. Respecto a los agentes evaluativos no se especifican los agentes evaluativos con un 43,5\% de las experiencias y, en las que sí lo hacen, la autoevaluación $(12,8 \%)$, un poco menos la coevaluación $(12,4 \%)$ heteroevaluación $(37,5 \%)$ y por tanto presentan porcentajes poco cercanos $(40,5 \%)$. 
Es necesario la selección de las dimensiones humanas en general y las que se puedan ampliar o dar como nuevo referente y la justa relación con las Inteligencias Múltiples, pero ¿Cómo analizar estos aspectos principales o dimensiones? ¿En qué detenernos? ¿Dónde había que fijarse para que el análisis fuera significativo y pertinente?

\section{Tabla 3: Evaluaciones Institucionales}

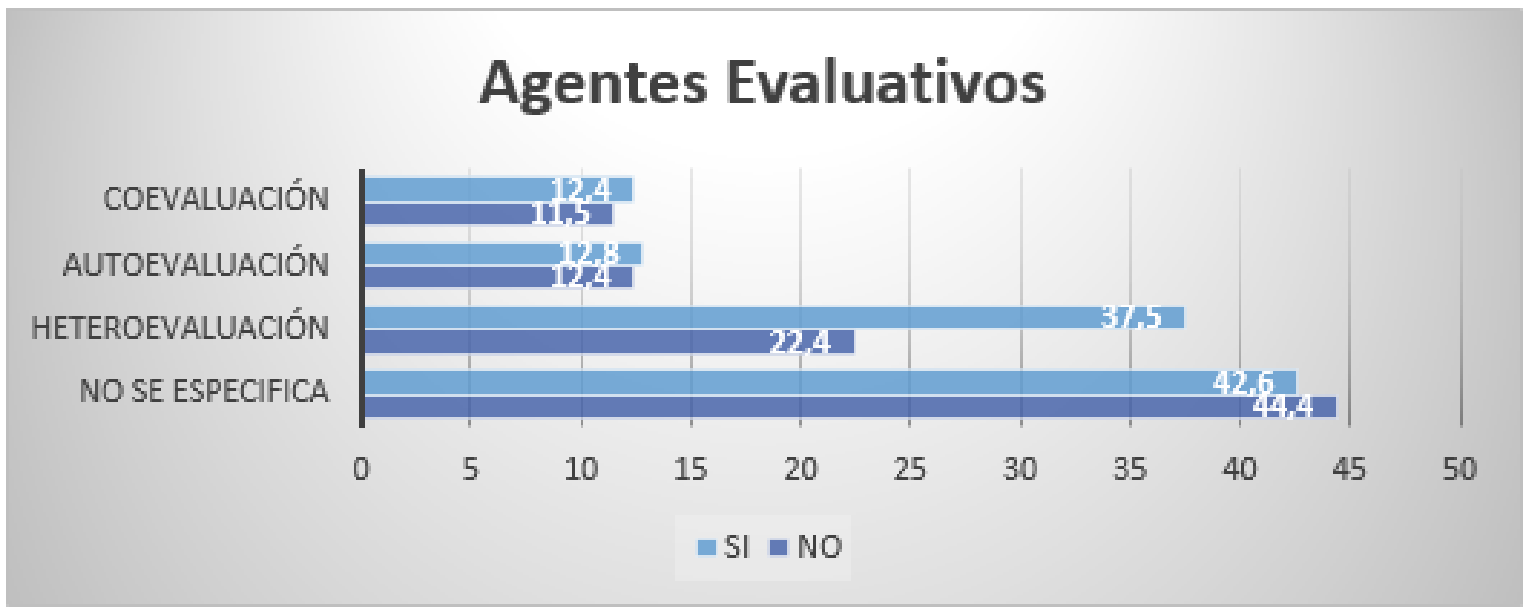

Luego de la autoevaluación y charla sobre las IM en el aula, se entiende y expresan la limitación que se hace de posibilitar otras opciones metodológicas prácticas para crecer y comprender a los demás y a sí mismo de potenciar sus saberes.

\section{Tabla 4: Conocimiento y Trabajo desde las Inteligencias Múltiples}

\section{Aplicación de Inteligencias Múltiples en áreas}

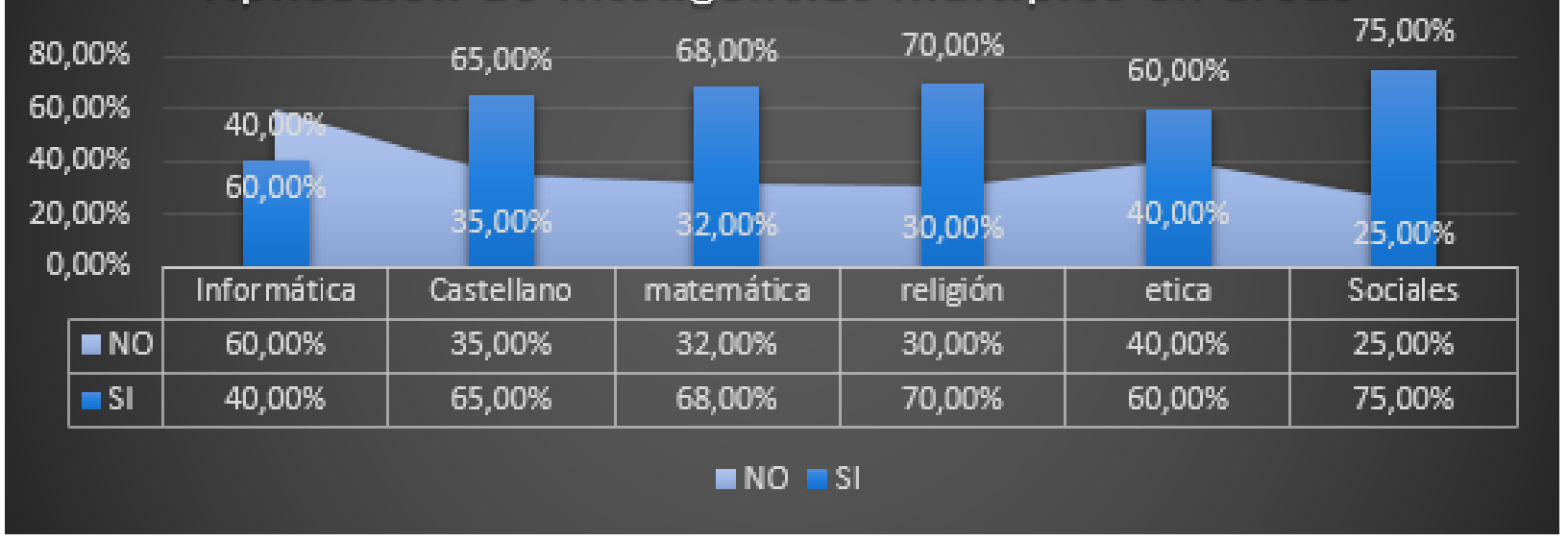

El procedimiento explica que un $37 \%$ no contempla el tema de las IM, o poco han investigado o que creen que su modo de enseñanza aprendizaje presenta poca variabilidad posiblemente por sus logros o seguridad que ofrece. El $63 \%$ de los maestros han percibido que la aplicación de distintas metodologías de trabajo, del compartir experiencias e innovar conforme al momento, al grupo y sus manifestaciones ha sido positivo para los logros. 


\section{DISCUSIÓN Y PROPUESTA}

Para alcanzar la calidad educativa se requiere del esfuerzo y compromiso de cambio aunado de docentes y directivos en correspondencia con las necesidades de su comunidad educativa. El actor capital es el docente motivado y direccionado desde su ser interior, que reflexione y responda desde sus posibilidades a armonizar sus acciones.

Así, el instrumento central: IALED o Instrumento de Autoevaluación del desempeño Laboral y Ético del Docente, acompañado de cuatro (4) guías instrumentales refuerzan la autoevaluación. Los cinco (5) Instrumentos en general, ofrecen la posibilidad de registrar y visualizar su valoración final a fin de asumir procesos estratégicos y especiales de mejoramiento generados por el docente interesado. Es una herramienta flexible, que permite modificar y alimentar elementos conforme a decisiones de los mismos maestros docentes y directivos. Es de gran utilidad práctica. Tiene las siguientes denominaciones:

1. Encuesta sobre las Inteligencias y prácticas reflexivas,

2. Aproximación a las inteligencias múltiples,

3. Evaluación a las actividades dirigidas y práctica reflexiva,

4. Encuesta general sobre ética profesional docente.

5. IALED - Instrumento de Autoevaluación desempeño Laboral y Ético del Docente.

El IALED, antes que evaluar al docente con algunos instrumentos empleados con los nuevos docentes regidos por el Decreto 1278 de 2002, le permite mayor progreso y son ellos mismos quienes confronten su desempeño mediante una herramienta de autoevaluación que consolida la calidad del servicio que ofrece. Fomenta la práctica evaluativa para el mejoramiento y calidad no sólo de su labor también de su vida en general, toda vez que la ética profesional apunta a estar, sentir y vivir bien. La propuesta es de apoyo al desarrollo profesional del profesorado en su vida $\mathrm{y}$ en la calidad del servicio educativo que brinda en su comunidad. El instrumento IALED, se estructura en tres (3) ámbitos (Curriculares, Gestión y Colaborativas) relacionados a su vez con las seis (6) Competencias Laborales Generales (CLG) que presenta el MEN en la Guía 21(Personales, Intelectuales, Emprendimiento, Interpersonales, Organizacionales y Tecnológicas).

El IALED, está en construcción y es susceptible de cambios, luego será flexible según las características del profesorado y de su entorno o contexto laboral; al mismo tiempo su utilidad se puede extender a otros actores de la comunidad educativa. Es un elemento importante para el proceso en el que un profesional formula juicios de valor sobre la pertinencia y efectividad de su propio desempeño en el ser, saber, hacer y convivir; en todo el actuar posible que pone en juego elementos éticos con principios y consecuencias en la tarea propia de ser humano en construcción o mejoramiento continuo. 
El nuevo modelo de evaluación ha sustituido la prueba escrita por un video que pretende evaluar el desempeño del docente; el directivo de la Institución realiza y acuerda elementos a evaluar anualmente, está también la autoevaluación y evaluación de los estudiantes. Es relativamente adecuado para analizar la didáctica, pero finalmente el video con el $80 \%$ es muy elevada la valoración quedando fuera elementos fundamentales que no hace mérito o justicia para ver o evaluar de forma holística al buen docente, al docente bueno y su mejor desempeño; no es el mejor indicador de las competencias que posee el maestro para favorecer el desarrollo integral propio y el de sus estudiantes. Se requiere garantizar primero que los docentes cualifiquen sus procesos de argumentación e interpretación y las universidades parece no ofrecer lo mejor en este sentido.

La utilización del modelo, requiere de elección voluntaria, lo que posibilita usar algunas metodologías, como el Informe libre, el test o cuestionario y listas de cotejo que indicarán en el punto del producto. Independientemente de la estructura metodológica utilizada para la autoevaluación debe ser complementada con otro modelo para validar o enriquecer éste ejercicio. Cada quien será el mejor juez de su desempeño y la autorreflexión fomenta mejoras en su ser profesional. Requiere de una cultura motivada y accionada por parte de todos los actores educativos, de reconocer su riqueza y beneficio personal e institucional. El modelo tiene ventajas relevantes, como:

- Los docentes son los mejores jueces de su desempeño.

- Se puede obtener información que es imposible observar con cualquiera de los otros modelos (percepción sobre el quehacer educativo, motivación, filosofía docente...)

- La autorreflexión por sí misma fomenta el cambio de las áreas de mejora del docente.

Este modelo, a su vez, tiene diversas desventajas que pueden limitar su uso:

- Requiere una cultura de evaluación por parte de todos los actores educativos.

- Implica una sensibilización a los docentes con el fin de disminuir el sesgo en su uso.

- No se recomienda como único modelo de evaluación docente.

- Generalmente no es usado con fines de diagnóstico o evaluación sumativa.

La Propuesta busca: Considerar la importancia de desarrollar fórmulas e instrumentos que respeten a la ética profesional y sin ser intrusivos, permitan reflexionar acerca de la función docente y sean facilitadores de la autoevaluación del profesorado, mediante el instrumento IALED u otros cercanos.

Una vez que se ha decidido la utilización del modelo, este puede desarrollarse por medio de tres posibles metodologías, como: informe libre, cuestionarios, y listas de cotejo.

\footnotetext{
$\overline{{ }^{14}}$ Unesco- Informe de la comisión institucional sobre la educación para el siglo XXI, presidida por Jacques Delors, págs. 95-109

${ }^{15}$ Op., Cit., Freire (2007). Pág. 73.
} 
- El informe libre, estrategia común en la auto evaluación docente, la cual requiere focalización en puntos como, sentido u orientación de su labor o desempeño educativo, actividades desarrolladas y nivel de satisfacción personal, metas alcanzadas, dificultades en las distintas gestiones, logros, aportes e investigaciones entre otros.

- Cuestionarios o test, existen ayudas, plantillas o guías dentro y fuera de las IE que pueden ser mejoradas o adaptadas para apropiar y dar sentido al interés de cada docente en el mejoramiento continuo de su acción pedagógica.

- Las rúbricas y listas de cotejo, es propio que la IE las utilice para evaluar el desempeño, sin embargo, el docente la puede usar y mejorar para retroalimentar y reflexionar su trabajo y vida, puede ir comparando en tiempos y espacios diversos donde cada uno redacta su auto evaluación.

El manejo del instrumento IALED permite que el mismo maestro pueda volver a revisar la guía evaluativa en distintos momentos, de forma libre y con la frecuencia moderada según su ritmo y querer. La participación activa de los docentes sobre impresiones, calidad y direccionamiento que ofrecen los ítems en cada uno de ellos y su pertinencia; se transcribe y se organiza para el diseño del Instrumento avanzando a una entrevista estructurada conforme a lo presentada en el IALED. Permitirá en posteriores trabajos y socialización, reflexiones que son un buen punto de partida para plantear y desarrollar los planes de formación de los próximos años en el Municipio de Ibagué.

El modelo y formatos no se incluyen por motivos de espacio y ajustes en el presente artículo.

\section{BIBLIOGRAFÍA}

Arelmí Beltramé, Tito (2016) Ética profesional y su relación con el desempeño docente en instituciones públicas de Juliaca. Revista Científica "Investigación Andina" Universidad Andina. Vol. 16 № 2. Juliaca-Perú. Págs. 97 - 110.

Armstrong, Thomas (2013). Inteligencias Múltiples en el Aula: Guía práctica para educadores. $5^{\text {a }}$. Edición. Ed/ Paidós. Barcelona. 279 págs.

Chávez G. Guadalupe y Benavides, Benigno (2011) Los profesores universitarios: entre la exigencia profesional y el compromiso ético-social. Revista electrónica Sinéctica No. 37. Universidad Jesuita de Guadalajara. Págs. 1-13

Freire, Paulo (2007). La Educación como práctica de la Libertad. Edición 53. Siglo XXI Editores. México. Págs. 153.

García López, R. Jóver, G. y Escámez; J. (2010): Ética profesional docente. Síntesis. Madrid.

Gichure Christine (2015). La ética de la profesión docente: estudio introductorio a la Deontología de la educación. Ediciones Universidad de Navarra S.A. - EUNSA

Hernández Sampieri R., Fernández Collado C., Baptista Lucio P. (2014) Metodología de la

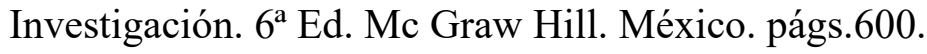


Hortal, A (2015) Ética general de las profesiones. Bilbao; Tercera Edición- Desclée De Brouwer. Pp 284

Margalef, L. Y Álvarez Méndez. J.M. (2005): "La formación del profesorado universitario para la innovación en el marco de la integración del Espacio Europeo”. Revista de Educación. Número 337 Mayo-Ag. Madrid. pp. 51-70

Marchesi, A. (2008), "Cambios sociales, emociones y los valores de los docentes", en Tenti Fanfani, E. (compi), Nuevos tiempos y temas de la agenda de política educativa, Siglo XXI.

Martínez Navarro, E. (2010). Ética Profesional de los profesores. Madrid: Desclée de Brouwer.

MEN (2013). Estándares básicos en competencias ciudadanas: formar para la ciudadanía sí es posible. Bogotá: Ministerio de Educación Nacional.

Nussbaum Martha C. (2011) "Sin fines de lucro. Por qué la democracia necesita de las humanidades". Rev. Signo y Pensamiento, vol. XXX, núm. 58, enero-junio, 2011, pp. 328-331. Disponible en: http://www.redalyc.org/articulo.oa?id=86020038025

OEI. (2010). Educación, valores y ciudadanía. Madrid: Fundación SM. [Fecha de consulta: 2 de diciembre, 2017].

Perrenoud, Philippe (2011). Desarrollar la práctica reflexiva en el Oficio de Enseñar. Crítica y Fundamentos 1. 4a . Reimpresión. Editorial Graó. Barcelona. 224 págs.

Rojas A., Carlos (2011) Ética profesional docente: Un Compromiso pedagógico Humanístico. Revista Humanidades. Universidad de Costa Rica. Vol. 1, págs. 1-22.

Savater, F. (2012) Ética de urgencia Editorial Planeta. Barcelona. Págs. 168

Torres, Manuel y Lajo, Rosario (2011). Relaciones entre ética profesional y desempeño laboral en profesores de un distrito del cono norte de Lima. Revista IIPSI. Facultad de psicología. Lima. Vol. 14 - N. ${ }^{\circ} 1$. Págs. $79-93$.

Unesco- (2009) Conferencia Mundial Sobre Educación Superior 2009: La nueva dinámica de la Educación superior y la investigación para el cambio social y el desarrollo. Pp13.

Vásquez Verdera, V., Escámez Sánchez, J., García López, R. (2012). Educación para el cuidado. Hacia una nueva pedagogía. Revista electrónica de investigación educativa - Estudios sobre Educación / Vol. 24 / 2013 / Págs. 269-272

Vélez, E. (2017) Los estudios sobre educación y sociedad en Colombia. Revista colombiana de educación. Universidad Pedagógica Nacional. Págs. 22.

Vitoria-Gasteiz, (2013). Mejora de la práctica docente Una experiencia de autoevaluación. RGM, S. A. Primera Edición. Gobierno Vasco. Págs. 87 